\title{
Power of Persuasion: Creative Communication in Business and Politics
}

\author{
Widodo Muktiyo \\ Professor in Communication Sciences \\ Universitas Sebelas Maret \\ Surakarta \\ muktiyo@yahoo.com
}

\begin{abstract}
Communication is so vital and powerful in social life. With communication, our lives become colorful. We interact, develop, and change in and within our social relation through communication. Communication is omnipresent in affecting all aspects of our life including in Business and politics. One of the important ways to conceive how communication works so powerfuly and beautifuly is by understanding the art of persuasion. Message plays an importantrole in the communication process that affects people. We can design and create a logical and persuasive message to influence others. The design of a message is similar to such of ghraphic design, web design, and visual imaging. Animation, composition, font, size and forms are some examples that show us that the power of persuasion is determined by the design of a message. Therefore, it can be concluded that communication can be used as an instrument to influence and affect people.
\end{abstract}

Keyword: Communication, art of persuasion, design of message, business, politics

\section{INTRODUCTION}

The notion of communication is so broad, either as a science that scholar develops in universities or as a phenomena within the society. Communication can be seen from many points of view. That is to say, so that we can fully understand it, we have to see communication from different perspectives. Besides, we can also sharpen our understanding about communication theories through communication levels, either interpersonal or group, including organizations or mass communication.

These give a variety of conceptions, premises, inter-connected explanations and philosophical foundations. It implies to whom that they devote much time to scrutinize communication, especially to get the best understanding from questions: what is communication? What is the nature of communication? Can we imagine what communication is? What is discussed?

These questions are rather difficult respond precisely. Harold D Laswell (1960) defined communication as "Who Says What in
Which Channel to Whom with What Effect". This formulation depicts that each of elements contributes significantly to the communication process as whole. Communicator, message, media, audience, and impact of communication have been given intense attention from many scholars around the world. They investigated each of the elements to raise new thought, interpretation, or innovation. Robert $\mathrm{T}$ Craig (1999), for instance, pointed out that many of them focus on messages, interaction, meaning, and technology; whereas others are interested more in meaning and interpretation. These practices constituted scientific traditions among them. In short, communication has multifaceted articulations. Communication can be defined as an interaction between sender and receiver, generating meaning or interchange of meaning and power as well.

Communication provides us an insight, information, imagination, and speculation or fantasy. We can use and change a society through communication. Social or individual identities were shaped by communication. To be successful in business, 
for example, we design and create so attractive products, so that customers like them. Also, so that the political campaign works effectively, we communicate through advertisements, posters, brand activations, promotional mixes, or face-to-face communication. That's all about communication and we need our passion to creatively realize it within the communication processes

To achieve all our purposes, we need the key: creativity. Message does not stand alone. It represents and symbolizes something. Symbols create meaning and signify an object to generate meaning. Symbols create imagination, identity, self presentation, or fantasies in accordance with the purposes or the goals that they will achieve. In other words, the way we create and design our message really determines the power of our communication. In rhetoric, we have the concept of ethos, pathos and logos. As a concept, logos is focused on how we produce a message, how we design it, how we make it in a sense of logic, how a message can be used as a tool to persuade others and work powerfully.

In any communication theoretical framework, messages play the most important role. We can see that discourse analysis is also focused on messages. Semiotics is also focused on messages. Conversation analysis also gives attention on messages. Shortly, messages are central in communication process. How we organize, present and receive messages affects us to think creatively.

\section{MESSAGE DESIGN}

The first important thing to make our messages powerful is the design of the message. We then need to identify the properties of messages such as type of letters, color, sound, tones, fonts, words, pictures, numbers, composition, combination, structures, line, dot, and size. Communication scholars do not stop at technical tones, but they continue to create and produce messages creatively. One of the parameters to think creatively is to ensure that messages will work effectively and efficiently when they were received or performed (Madison \& Hamera, 2006). For communication scholars, the most important thing is not the aesthetics issues, but on how we can create a message that affects people in line to the goals that will be accomplished.

Communication scholars do not ignore aesthetics nuances. However, the power of message is more important than aesthetics. They also understand that technology may help and technically support to make the design of messages with beautiful taste and beautiful compositions (Schirato \& Webb, 2004). Technology of computer has transformed and revolutionized desktop publishing. Digital technology does not change a function of letter, for instance, as an element of visual communication. Technology just provides a variety of spectrum in designing, producing, and presenting a message. Technology also opens a broader of expression in articulating message, visual communication, or digital imaging (Straubhaar/La Rose, 2006).

At this point, one the one hand, we find a cross-section among studies of communication. On the other hand, we see technology affecting the field, directly or indirectly. First, we know there are the fields that are focused merely on message design, like visual communication studies, typography studies, computer graphics, and web design, as well as digital imaging. Technology plays a central role in determining those studies. Secondly, the impact of technological development affects studies that are focused on the way an individual thinks creatively in designing and creating a powerful message. They observe dimension of persuasion to get the best effect of the message design. Psychology and sociology, in this case, are involved intensely in determining some of dimension in persuasion (Brock \& Green, 2005).

As the art of influence, persuasion itself includes three dimensions that determine effectiveness: logos, ethos, and pathos (Lawson \& Tancred, 1991). First, logos is about the message design, style of argument, reason and logic of message, composition of message, and selection of diction. Secondly, ethos is about communicators. It encompasses three aspects: characters, intelligence, and goodwill. Thirdly, pathos is about aspect of 
emotion. The effectiveness of communication depends on these three aspects.

\section{BUSINESS AND THE ART OF PERSUASION}

Communication industry in Indonesia has been increasing since two decades ago. The number of creative talents who work in communication industry also increases rapidly. New requirement is now needed in line to the increasing demand for creative communication talents like copywriters, photographers, editors, art directors, creative directors, programmers, animators, designers, presenters, reporters, and so on. They work with an innovative, energetic, and artistry style. Nobode can refute this. This trend signifies the winning of communication capitalism when means of communication are transformed into means of production. Many have oriented their life to seek the best take-home pay for creative jobs. This is what Francois Fukuyama forecasted that when capitalism wins the competition, the history will end. History of the world is telling the story of capitalism.

I am going to emphasize that business, industry, and trends of capitalism today are moving to creative industry where management of impression is becoming the core of creative communication industries to make customers, or politicial constituents, believe and trust us. If they behave as what we wish, we can take opportunity to manage and organize them to produce benefits and advantages. They will buy our products or vote for us. One of the important things to make impression is the art of persuasion. For this reason, I emphasize here that communication is very important to affect an individual behavior and the best way to significantly affect people is the power of persuasion.

Mode of culture and consumption is shaped and affected by communication in which persuasion plays a role in making beautiful impression. On behalf of creativity and art of persuasion, we see clearly how size and form of desktop or laptop are changing day per day, becoming more attractive, more interesting, and more unique. We also see how Alibaba as an enterprise has developed very rapidly because creative communication talents, like Jack Ma, do the job well. Movies like Star Wars, Jack Sparrow, Harry Porter, and other successful movies are also directed by creative people. Lifestyle, fashion, film, music, design, and others, are all managed and polished by creative people.

Communication industry also triggers a big amount of expenditures and spends much money while also getting revenue in return of the investment within this industry. So, as means of production, communication industry can make money faster than manufacturing industry. They come to communication to seek opportunities and maximize their profit in their business. Many integrate conventional ways of business, technological development, creativity, and art to modernize the society. People are exposed more to pragmatism and consumerism and becoming so trivial. Thus, I can say that art of persuasion is so powerful in influencing the society, especially in business enterprises.

\section{PERSUASION IN POLITICS}

I have two premises about communication and politics. First, man is a using-symbol animal. By symbol, a man can present, reflect, and even deflect reality. This premise shows that man is communication human being. The second premise is that politics is about who gets what, when, and how. The question is how do these premises have inter-related each other.

In this sense, communication is frequently used as an instrument to influence and control power (O'Shaughnessy, 2004). It is so interesting when we observe what Manuel Catells (2009) said about power. According to him, power is the most fundamental process in society since society is defined around values and institution and what is valued and institutionalized by power relations. Communication plays an important role in power relation and exercise of politics. By communication, politician can present, reflect, and deflect reality. Language and symbols can construct and re-construct ideas, opinions, frames of reference, narrations, or types of stories. 
Theories of power address the relationships among social actors, communities, and the broader society including a state. Societies are not just collectivities of people but are also about sharing of values and interest. We need to read theories of power to understand how it intervenes in the process by which social actors are provided with the life chances that enable them to realize particular goals, identities, and forms of differences. The ideas of ruling class in every epoch that is always the ruling material force of society and ruling intellectual force (Mumby, 2011)

Why do politician do these? Because they want to influence others. In an election, they want to influence people to vote for them. In a parliament meeting, they discuss and argue to convince each other for decision or policy making. In a campaign, they want to socialize the programs so that people know. In short, politician devote their power, position, occupations, or interests.

What is the most important thing that we can see from these behaviors? I can see that communication and politics are very close and involving each other. They are interdependent. In other words, what we see as political activities are actually communication events. By social construction of reality approach, communication events can be constructed or created in accordance with the purposes. Labeling, stereotypes, self of fulfilling prophecy, naming, and imaging are products of communication. All of them can be created for political reasons and thus can be perceived as political nuances.

In my opinion, the terms of creation and construction in communication fields must be related to design, art, and aesthetics. Creation and construction are words to refer to design, model, prototype, and craft. All of political products as communication events definitely can be strategies to get the best impact and influence to people. So it is common to say that a good politician is good communicator, or vice versa. The results communication construction can be valued in line to their character, intellectuality, and motives.

\section{ETHICS AS CONSIDERATION}

Either communication as an art of persuasion or as an instrument of power in politics and business, we must consider ethics and moral implications as the consequences of the implementation in the design of communication (Cheney, May, \& Munshi, 2011). Currently, moral and ethical judgement is debating. Many see it as unquestionable cause of implication of liberation and tehnology development raising what we call it as post truth era or disruption era, whereas other see it seriously cuase affecting people do misconduct and deviant. The most important judgement related to ethics and moral consideration is to question how to build a good design of message without violating social norms, religion values, social arrangement, and the regulations.

Issues of liberation, unethical visual, hatred of visual design, and blasphemy (Marshall \& Shea, 2011) are examples that can be classified as message design that violates ethichs or make controversies in society. We must be wise that each message can probably be in accordance with the purpose of communication. Messages that are actually created intensely to win competition either in business or politics can even hurt the society, when the messages are not compliant with the social norms and ethics.

Therefore, ethical and moral judgment for every designer, animator, presenter, content creator, creative and art director, stylist, and other creative talents who have dedicated their life in communication industry is really important. We cannot ignore problems of ethics although we are expert and experienced in this field. Whatever we do professionally it will be useful and purposeful if we always consider moral and ethical judgment in every design that we have produced.

\section{REFERENCES}

Brock, Timothy C and Green, Melani C, 2005, Persuasion Psychological Insight and Perspectives, Thousand Oak: Sage Publication 
Castells, Manuel, 2009, Communication Power, New York: Oxford University Press

Cheney, George, May, Steve, and Munshi, Debashish, 2011, The Handbook of Communication Ethics, New York: Routledge

Craig, Robert T, 1999, Communication Theory as a Field, Communication Theory, Vol 9, pp. 119-161

Laswell, H.D, "The Structure and Function Communication in Society", in L. Bryson (ed), 1960, The Communication Ideas, New York: Harper and Bros

Lawson, H.C and Tancred, (translation), 1991, Aristotle The Art of Rhetoric, London: Penguin Classic

Madison, Soyini and Hamera, Judith,2006, The Sage of Handbook of Performance Studies, Thousand Oak: Sage Publication

Marshall, Paul and Shea, Nina, 2011, How Apostasy and Blasphemy Codes Are Silenced Choking Freedom Worldwide, New York: Oxford University Press

Mumby, Dennis K, " Power and Ethics, in Cheney, George, May, Steve, and Munshi, Debashish, The Handbook of Communication Ethics, New York: Routledge

O'Shaughnessy, Nichols Jackson, 2004, Politics and Propaganda Weapons and Mass Seduction, Ann Arbor: Michigan University Press

Schirato, Tony and Webb, Jen, 2004, Understanding thevisual, NSW: Allen and Unwin

Straubhaar/La Rose, 2006, Media Understanding Media, Culture and Technology,Wrdworth: Thompson 